\title{
A InfluÊncia da Estratégia de Vínculos INTERORGANIZACIONAIS SOBRE A DINÂMICA de Micro e Pequenas Emipresas
}

\author{
Bruno Tavares \\ DatdorandbemAdministraçãopda UnivesidadeFedaral de \\ Lavras MestreemExtensão Rural pda UnivesidadeFedral de \\ Vicosa eProfessor A ssistenteda Universidade Federal deV icosa \\ btavares@ufvbr \\ Luiz Marcelo Antonialli \\ Dattor emAdministração pda FEA-USPe \\ Professar Adjuntoda UniversidadeFederal deLavas \\ lmantonialli@ud.combr \\ Cleber Carvalho de Castro \\ DattoradoemAgronegóios pda Univesidade \\ Feekal db RioGrandedb Sul eProfessor Adjunto \\ da UniversidadeFeekral deLavras \\ deberastro@ufla br
}

\section{RESUMO}

\begin{abstract}
As interações interorganizacionais importam significativamente para a eficiência das organizações e representam uma estratégia por meio da qual as micro e pequenas empresas (MPE) superam as suas limitações. Este artigo objetiva identificar os elementos característicos das micro e pequenas empresas que podem sofrer influência da adoção da estratégia de redes, definidas como o estabelecimento de vínculos interorganizacionais estáveis. Para tanto, foram pesquisados artigos dos anais do E ncontro de estudos sobre empreendedorismo e gestão de micro e pequenas empresas (EGEPE) que relatavam estudos empíricos sobre o tema, além de referências sobre as MPE e as redes. Ao final, são identificados mecanismos pelos quais as redes interferem nas características das MPE, e conclui-se que os vínculos interorganizacionais caracterizam-se como estratégia favorável às MPE, pois podem fornecer vantagens por meio das economias de aglomeração e pela obtenção de benefícios não alcançáveis pela empresa caso ela atue de modo isolado.
\end{abstract}

Palavras-chave: Pequena Empresa. Rede. Estratégia.

\section{ABSTRACT}

Inter-organizational interacions matter sigificantly to the efficiengy of organizations and represent a strateyy by which micoand small eterpises (MSEs) atweigh ther limitations This artideains at idantifjingthecharacteisticfeetures of micoand small eterpises that may beinfluened by theadqption of nework strategy, defined as theestablisment of stableinter-cromizational ties Thus this work has examined artides fromAnnals of Meting of Studiesin Entreprenership and Management of Mico and Small Enteprises (eGEP) which reparted empirical sudies on thesubet, as wdl as referenes on small business and neworks In condusion, this artide identified mehanisms by which neworksinterferein the haracteistics of theMSEs and conduded that inter-arganizational tiesaredaradeized as a favcrablestrateey to MSEs sincetheycan proidebenfits thragh economies of aggomeration and thedbtaining of benefits not adievableby a companyif it adtedin isdation

Keywords: Small Business Network. Strategy. 


\section{IN TRODUÇÃO}

$\mathrm{O}$ estudo das redes interorganizacionais justifica-se em diversas dimensões analíticas. Empiricamente, as organizações em rede consolidaram-se como um novo paradigma produtivo resultante das condições de incerteza ambiental (CASTELLS, 1999 e BEST, 1990). Economicamente, as cifras monetárias envolvidas são eloquentes: no ramo de supermercados, por exemplo, as redes e associações faturaram, em 2006, quase 16 bilhões de reais (GAZETA MERCANTIL, 2007). No campo político, as redes constituídas por meio de aglomerações empresariais são um dos objetos centrais das políticas públicas recentes, tanto governamentais como de entidades como 0 Serviço Brasileiro de Apoio à Micro e Pequena Empresa Sebrae (ROVERE, 2002 e SE BRAE, 2003). No âmbito teórico, autores como Nohria (1992) e Britto (2002) destacam a importância e a validade dessa perspectiva analítica.

Tendo como recorte as micro e pequenas empresas, o estudo dos vínculos interorganizacionais estáveis (redes) é particularmente importante, dado que essa forma organizacional inclui também a perspectiva estratégica. Autores como O lave e Amato Neto (2001) e Balestrin e Vargas (2004) destacam que as redes interorganizacionais são uma alternativa favorável para a obtenção de competitividade perante outras micro e pequenas empresas, e também como forma de competir com as grandes empresas.

Embora seja um tema que tem recebido atenção crescente em eventos e publicações acadêmicas (BEGNIS; PEDROZO; ESTIVALETE, 2005), uma relação pouco estudada é a influência das redes sobre as formas de gestão.

Dessa forma, o problema abordado neste estudo é: quais as implicações para a dinâmica organizacional de micro e pequenas empresas decorrentes da adoção da estratégia de vínculos interorganizacionais estáveis? 0 objetivo é identificar, a partir da reflexão teórica e de resultados empíricos já publicados, os elementos característicos das micro e pequenas empresas que podem sofrer influência da adoção da estratégia de estabelecimento de vínculos interorganizacionais estáveis.

Para a verificação da influência da adoção da estratégia de rede sobre a gestão das micro e pequenas empresas, foram analisados artigos dos anais do Encontro de Estudos sobre Empreendedorismo e Gestão de Micro e Pequenas Empresas (EGEPE), das cinco edições do evento (2000, 2001, 2003, 2005 e 2008), que relatavam estudos empíricos sobre 0 tema. A análise foi realizada partindo-se das categonias da gestão das micro e pequenas empresas e das vantagens da estratégia de redes, apontadas por documentos científicos (artigos, livros, relatórios, entre outros), buscando a identificação de fontes e mecanismos de influência das redes e seus possíveis impactos na gestão de micro e pequenas empresas.

Para cumprir esse desafio, a próxima seção procura evidenciar as particularidades das micro e pequenas empresas que as identificam como um enclave organizacional específico. Posteriormente, a seção 3 caracteriza as relações interorganizacionais como estratégia favorável à sobrevivência e ao desenvolvimento das micro e pequenas empresas.
Em sequência, são apresentados o método e os procedimentos utilizados no desenvolvimento do trabalho. As seções $5 \mathrm{e}$ 6 descrevem os resultados da análise, apontando, respectivamente, a influência do estabelecimento de vínculos interorganizacionais estáveis sobre a gestão de micro e pequenas empresas e uma proposta de tipologia dos mecanismos pelos quais essa influência se dá. Por fim, são apresentadas considerações a respeito do estudo e de perspectivas de pesquisas futuras.

\section{PARTICULARIDADES ORGANIZACIONAIS DAS MICRO E PEQUENAS EMPRESAS}

As micro e pequenas empresas são apontadas como importantes para o desenvolvimento econômico e social, como estruturas ágeis e com elevada capacidade de resposta às demandas devido à elevada flexibilidade organizacional (CASTELLS, 1999). Assim, quais seriam os fatores relativos ao pequeno porte que podem obstar o desenvolvimento das micro e pequenas empresas? Esse é o foco desta seção.

As micro e pequenas empresas são um objeto de estudo complexo, de difícil definição e com elevada heterogeneidade. Em termos quantitativos, o número de funcionários é um dos critérios mais utilizados para inferir sobre a complexidade organizacional. Segundo o Sebrae (2008), são microempresas aquelas que atuam na indústria ou no setor de construção civil e que possuem até 19 funcionários, ou que atuam no setor de comércio e serviços e que empreguem até 09 funcionários. As empresas de pequeno porte da indústria e da construção são aquelas que possuem entre 20 e 99 funcionários, e as do comércio ou serviços aquelas que empregam entre $10 \mathrm{e}$ 49 funcionários. Todavia, neste artigo, serão tratadas microempresas e empresas de pequeno porte indistintamente sob o conceito amplo de micro e pequenas empresas (MPE), dado que ambas possuem características organizacionais suficientemente semelhantes para os fins aqui propostos.

Para um entendimento mais profundo do segmento, porém, deve-se atentar para compreender as características que diferenciam as micro e pequenas empresas das grandes empresas.

Como elemento central é apontado, com unanimidade entre os autores que discutem a definição de pequena empresa, o papel do empreendedor-proprietário. A história de vida do empreendedor-proprietário, as experiências em sua formação profissional e suas relações pessoais e familiares são condicionantes da dinâmica tanto interna quanto externa da pequena empresa (RATTNER, 1985). Sob muitos aspectos, a pequena empresa é uma externalização do pensamento e da ação do próprio empresário, com ele confundindo-se em sua história e dele dependendo em sua dinâmica (D O LABELA, 1999).

Essa relação íntima entre empresa e empreendedor extrapola 0 âmbito das descrições e assume um caráter conceitual importante. Alguns autores consideram a autonomia do empreendedor como elemento fundante da pequena empresa, gerando a exclusão das franquias dessa categoria de análise (LIMA, 2001). A legislação brasileira pertinente, des- 
de o primeiro momento (BRASIL, 1999), incorporou essa opinião ao não permitir o enquadramento das pessoas jurídicas de cuja constituição fazem parte outras pessoas jurídicas como microempresa ou empresa de pequeno porte.

A gestão de micro e pequenas empresas decorre dessa condição essencial e caracteriza-se por ser centralizada no proprietário (BARBOSA; TEIXEIRA, 2003), sendo a racionalidade econômica insuficiente para compreender as decisões tomadas. Paralelamente ao âmbito empresarial, encontram-se as dimensões política e familiar, as quais condicionam profundamente as suas atividades (LEONE, 1999). Além disso, é comum a existência de sistemas gerenciais simples e pouco eficientes, havendo até na base de dados contábeis pouca confiabilidade devido à elevada sonegação (KASSAI; KASSAI, 2001). Mesmo o advento dos sistemas informatizados, os quais muitas já implantaram, não foi suficiente para se fazer crer que a dinâmica da gerência incompleta (LIMA, 2000 e SILVA, 2002), personalizada e baseada mais na experiência do que em fatos tenha sido alterada.

A escassez de recursos também está entre as categorias relevantes para a compreensão das micro e pequenas empresas. Manifestada em termos tecnológicos, financeiros, humanos e materiais, pode ser uma das categorias na qual a heterogeneidade seja mais presente, em especial quando se considera os diferentes setores. Todavia, considerando as micro e pequenas empresas comparativamente às grandes empresas, justifica-se atribuir ao volume de recursos disponíveis internamente um fator relevante da dinâmica organizacional (WELSH; WHITE, 1981 e CONFEDERAÇÃO NACIONAL DA INDÚSTRIA - CNI, 2006).

Como reflexo, as micro e pequenas empresas pagam menos aos seus funcionários (NAJBE RG; MO RAES; IKEDA, 2002), os quais são menos qualificados e multifuncionais, possuem processos produtivos menos avançados tecnologicamente, sistemas de gestão parcialmente implantados (LEO NE, 1999, LIMA, 2000 e TAVARES; FERREIRA; LIMA, 2008) e recorrem prioritariamente a fontes internas de recursos para promover o seu desenvolvimento (LIMA, 2001). A escassez também provoca dificuldade na obtenção e no acesso a recursos avançados, o que restringe o desenvolvimento das micro e pequenas empresas.

No âmbito externo, os estudos apontam que, geralmente, as micro e pequenas empresas atuam em mercados restritos (GIMENEZ, 2000), possuem dificuldade de acesso ao crédito (KASSAI; KASSAI, 2001) e pouca influência sobre as políticas governamentais (RATTNER, 1985 e KASSAI, 1997), e adotam estratégias reativas de adaptação ao ambiente (LEO NE, 1999). Além disso, têm dificuldade de acesso à tecnologia e possuem pouco ou nenhum poder de negociação com fornecedores e clientes.

Em suma, as principais características das micro e pequenas empresas são:

a) importância central do empreendedor-gerente como elemento dinamizador;

b) baixa profissionalização e utilização parcial de práticas gerenciais; c) configuração tecnológica defasada ou dificuldades em desenvolver e sustentar progresso técnico;

d) mão de obra multifuncional e pouco qualificada;

e) dificuldade de acesso a fontes de informações e tecnologias;

f) escassez de recursos financeiros;

g) pouco poder de negociação;

h) atuação em mercados limitados;

i) sistemas de informação simples e pouco eficientes.

Essas características de gestão podem ser reunidas em três categorias: a) autonomia e centralização; b) gestão incompleta e escassez de recursos, e c) pouca influência sobre 0 ambiente, descritas a seguir.

Em termos de Autonomia e centralização, sendo uma exteriorização do empresário, as micro e pequenas empresas tendem a ter uma gestão autocrática e centralizada, marcada tanto por elementos de racionalidade econômica quanto por fatores culturais e familiares diversos. Por gestão incompleta e escassez de recursos entendem-se as grandes dificuldades enfrentadas pelas micro e pequenas empresas no que diz respeito à racionalização de recursos internos e à obtenção de recursos críticos e, portanto, de custo elevado. A pouca influência sobre o ambiente possui relação íntima com a categoria anterior. Muitas das oportunidades percebidas podem não ser aproveitadas, pois, muitas vezes, as micro e pequenas empresas têm uma atuação restrita a mercados marginais ou localizados (nichos), além de pouco poder de negociação com fornecedores e clientes.

Na próxima seção são apresentados conceitos centrais e reflexões para o estudo dos vínculos interorganizacionais, e os potenciais benefícios advindos da adoção dessa estratégia por parte das micro e pequenas empresas.

\section{RELAÇÕES INTERORGANIZACIONAIS COMO ESTRATÉ GIA}

As relações interorganizacionais assumem diversas configurações, sendo as redes as mais comuns atualmente. Assim, este estudo privilegia as relações em rede. Mas o que são as redes? Existem muitas definições e há pouca convergência sobre uma definição amplamente aceita, gerando mais uma cacofonia conceitual do que uma consolidação de formas de análise (SANTO S; TEIXEIRA, 2005).

Williamson (1985) advoga que as redes são organizações híbridas, caracterizadas por ser um ponto intermediário entre a hierarquia e 0 mercado, e adequadas às condições nas quais nenhuma dessas formas puras atendam adequadamente aos critérios de especificidade dos ativos e da frequência das relações. Essa visão é combatida por autores próximos à sociologia econômica, como Powell (1990) e Nohria (1992), os quais entendem que as relações interorganizacionais não podem ser entendidas apenas como formas de reduzir os custos de transação. Ao contrário, são estruturas que emergem das relações sociais nas quais as transações econômicas estão enraizadas.

Na vertente da Organização Industrial, Britto (2002) define as redes como arranjos interorganizacionais baseados 
em vínculos sistemáticos entre empresas independentes, originando uma forma específica de coordenação das atividades econômicas. De modo semelhante, Castells (1999) entende as redes como um sistema cujos meios são intersecção de segmentos autônomos.

Há ainda outras abordagens teóricas e analíticas especialmente voltadas à sociologia que poderiam seridentificadas. Todavia, tal discussão foge do escopo deste artigo. Entre as fontes que podem ser buscadas, encontram-se Grandori e Soda (1995), Powell (1990) e Nohria (1992).

Para os objetivos ora propostos, ressaltam-se os aspectos de autonomia, mesmo que relativa, das partes envolvidas e a importância da interação e da coordenação das relações que são elementos comuns aos autores citados. Mais especificamente, este artigo tem como objeto um tipo específico de rede, a saber: as relações estáveis estabelecidas entre micro e pequenas empresas para a obtenção de vantagens e objetivos comuns.

\section{ELEMENTOS DE CONTEXTO NA FORMAÇÃO DAS REDES NO BRASIL}

Embora se reconheça a forte influência que os elementos de natureza social, econômica e institucional exercem sobre o objeto de pesquisa, a delimitação de um contexto específico, no âmbito deste artigo, é complexa. Isso ocorre devido à multiplicidade de setores envolvidos na análise por meio da revisão bibliográfica em outros artigos empíricos. Além disso, o próprio objeto não é homogêneo, mas multiforme. Assim, o contexto apresentado, que não tem a pretensão de ser exaustivo, visa destacar elementos relevantes que contribuem para o entendimento do objeto, ainda que não interfiram diretamente sobre a análise.

Um primeiro aspecto refere-se à abertura econômica ocorrida na década de 1990, que facilitou a entrada de produtos importados no mercado nacional. No âmbito das grandes empresas, houve o fenômeno das fusões e aquisições, alterando a configuração patrimonial das empresas aqui instaladas (MIRANDA, 2001). Ademais, houve uma pressão para se adotar novas formas de gestão, típicas do que viria a ser caracterizado por redes internas e por cadeias de suprimento. São exemplos a adoção das práticas de administração japonesa (toyotismo), a terceirização em massa de "atividades meio" e o estabelecimento de contratos de longo prazo com um número cada vez menor de fornecedores (FARAH JÚNIOR, 2000).

As micro e pequenas empresas sofreram influência de tais ações. Por exemplo, muitos executivos "desempregados" pelos programas de terceirização e "downsizing" das grandes corporações criaram o próprio negócio, às vezes vinculados à grande empresa anteriormente empregadora, às vezes não. Pela maior experiência com gestão e por nível mais elevado de escolaridade, esse público proporcionou um segmento dentro do segmento das pequenas e médias empresas, carac terizadas pelo maiornível de profissionalização (FONTOURA, 1996). Outra decorrência foi o estreitamento das relações entre grandes empresas e seus fornecedores, com a exigência de um maiornível de profissionalização delas (SOUZA, 1995).
Além disso, o Sebrae adotou como função central a promoção do desenvolvimento regional por meio do empreendedorismo (SEBRAE, 2003). Isso estimulou a formação de redes locais, conhecidas como arranjos produtivos locais (APLs), os quais sofrem forte influência institucional (TAVARE S; LEITE; CASTRO, 2007).

Todos esses fatores, em conjunto, parecem corroborar o pressuposto de que as interações interorganizacionais importam significativamente para a eficiência das organizações (BRITTO, 2002 e CAST ELLS, 1999).

\section{A ESTRATÉGIA DE REDE COMO VANTAGEM COMPETITIVA}

As mudanças de natureza múltipla das décadas de 1970 e 1980, refletidas no Brasil dez anos mais tarde (FARAH JÚNIOR, 2000 e CO UTINHO, 1995), a partir do processo de ajuste econômico (MIRANDA, 2001), influenciaram e exigiram uma adaptação por parte das organizações, que buscaram formas de reduzir a incerteza ambiental e aumentar a capacidade de resposta ao ambiente. Essa reestruturação industrial gerou uma nova forma de competição entre as empresas (BE ST, 1990).

As relações interorganizacionais e a estrutura interna das empresas emergem dessa necessidade e passam a constituir uma estrutura necessária e coerente com a estratégia e maior flexibilidade. Como apresentado por Mintzberg, Ahlstrand e Lampel (2000), essa relação entre estrutura e estratégia encaixa-se numa das primeiras escolas de estratégia. Inaugurada por Alfred Chandler com seu livro Strateyy and Structure, de 1962, a noção de que estrutura segue a estratégia foi observada a partir dos "estágios estruturais" pelos quais as empresas passam, sempre com vistas a obter coerência com as exigências ambientais.

O primeiro estágio é representado pela aquisição de recursos que poderia se dar pela integração vertical, internalizando atividades, ou pela consolidação de empresas já existentes, como adotado pela General Motors. 0 aumento da complexidade organizacional conduziu a segmentação interna, criando a estrutura funcional que deu origem às quatro grandes áreas da gestão: produção, finanças, comercial e recursos humanos. Após essa reorganização, há uma nova fase de expansão para novos mercados ou mesmo para negócios inteiramente distintos, dando origem aos grandes conglomerados com atuação diversificada. Esse processo culmina com o "corolário" necessário à produção em massa da grande empresa integrada (WO OMACK; JONES; RO OS, 1992), representado pela empresa divisionalizada, o que possibilitava a descentralização das decisões e a manutenção do controle por meio dos resultados de cada unidade.

Miles e Snow (1992) avaliam que a estrutura em rede é fruto dessa evolução estrutural, representando o modo organizacional hodierno mais adequado. Assim, as redes representam uma nova matriz organizacional (CASTELLS, 1999), na qual devem ser buscadas as novas fontes de eficiência produtiva (BRITTO, 2002). Trata-se de um arranjo que transcende as fronteiras burocráticas e tornam a definição 
dos limites organizacionais mais tênues (SANTOS; EISENHARDT, 2005).

As redes também podem ser concebidas para a obtenção de vantagens competitivas às quais as micro e pequenas empresas não obteriam acesso, caso atuassem de modo isolado. As grandes empresas também buscam vantagem competitiva por meio das relações organizacionais. Todavia, enquanto as últimas obtêm, principalmente, economias de escopo, as primeiras podem aproximar-se das vantagens de economias de escala típicas das grandes unidades empresariais.

Assim, entendendo estratégia como o modo de se obter vantagens competitivas em relação aos concorrentes por meio do posicionamento adequado às condições ambientais (PO RTER, 1986, 1989), as redes representam uma estratégia importante para que micro e pequenas empresas consigam maior poder de negociação perante os fornecedores e clientes. Além disso, podem influenciar nas barreiras de entrada e na rivalidade entre as empresas do setor. Assim, reconhecendo que o estabelecimento de vínculos estáveis entre micro e pequenas empresas tem se apresentado em alguns setores de modo muito frequente, as redes podem ser identificadas com 0 modo pelo qual elas competem e obtêm maiores vantagens, isto é, um "padrão de concorrência" do qual devem se aproximar, com vistas à obtenção de maiores ganhos (FE RRAZ; KUPFER; HAG UE NAUER, 1995).

Redes, identificadas como vínculos interorganizacionais estáveis, particularmente entre micro e pequenas empresas, portanto, representam estratégias em dois sentidos: a) alteração estrutural para adequação às exigências do ambiente, e b) decisão empresarial para obtenção de vantagem competitiva.

As formas de rede mais comuns entre micro e pequenas empresas são:

a) Arranjos produtivos locais: são aglomerações, em determinado território, de empresas relacionadas a um mesmo setor que possui participação significativa na economia regional. G eralmente há a participação do poder público e/ ou de instituições de apoio, como o Sebrae. No caso do Brasil, a relação entre os empresários visa à obtenção de benefícios conjuntos, e a realização das atividades é conciliada por meio de um "acordo de resultados".

b) Centrais de compra ou de negócios: são associações constituídas pela formalização da rede, geridas pelos próprios membros ou por terceiros, em que é cobrada uma mensalidade. Pode tanto restringir-se a reunir compras de seus membros para reduzir custos ou oferecer serviços múltiplos como pode gerenciar crédito dos clientes dos associados.

c) Consórcios: são entidades que reúnem micro e pequenas empresas normalmente para divulgar os seus produtos em mercados que não seriam passíveis de atingir pela ação isolada. No geral, são feitas vendas em conjunto, podendo haver a constituição de uma marca comum.

d)Organização virtual: refere-se à utilização da tecnologia da informação para a interação entre empresas.
Pode ocorrer em qualquer das formas anteriores ou assumir uma forma própria, de modo a coordenar a produção conjunta das empresas-membros.

Os principais benefícios apontados na teoria sobre redes de micro e pequenas empresas são (BALESTRIN; VARGAS, 2004; CASSIOLATO; LASTRES, 2003, CEZARINO; CAMPOMAR, 2005 e SANTOS; TEIXEIRA, 2005):

a) aprendizagem coletiva;

b) aumento do poder de negociação;

c) acesso a novos mercados;

d) melhorias gerenciais;

e) redução de custos de transação;

f) economia de escala;

g) economia de escopo e especialização;

h) maior acesso a recursos;

i) aperfeiçoamento tecnológico de produtos e processos.

A seguir, é descrito o método e os procedimentos utilizados na realização deste estudo.

\section{MÉTODO E PROCEDIMENTOS}

O presente estudo caracteriza-se como uma metanálise, tipo de pesquisa, segundo Lovatto, Lehnen e Andretta (2007), que se distingue pela combinação de resultados de estudos independentes, e que começou a se estabelecer a partir do final dos anos 50, embora tenha se difundido apenas nos últimos 20 anos. A sua aplicação estende-se por todos os campos científicos, incluindo as ciências naturais e as sociais.

Em administração, os trabalhos de Botelho e Macera (2001), Gosling e Gonçalves (2004) e Jabbour, Santos e Barbieri (2008) são apresentados como exemplos de metanálise e enfatizam a categorização de artigos publicados segundo itens previamente determinados. No entanto, outros estudos, que também são definidos como metanálise, possuem uma perspectiva um pouco diferente, da qual este trabalho se aproxima, em que são utilizados resultados publicados de diferentes estudos para a elaboração de afirmações mais amplas. São exemplos dessa metodologia os trabalhos de Brodeck et al. (2003), Bujdoso et al. (2007) e Rodrigues (2002).

A metanálise se utiliza de dois tipos de dados: os quantitativos e os qualitativos. Q uando os estudos analisados apresentam dados quantitativos, são elaborados metadispositivos experimentais de modo a ampliar as conclusões ou identificar novas hipóteses. A metanálise qualitativa (MCCO RMICK; RO DNEY; VARCOE , 2003) não possui um modelo analítico consolidado, aproximando-se, todavia, dos dados quantitativos no que se refere à sua finalidade: ampliar resultados de estudos anteriores ou desenvolver novos insightspara pesquisas futuras. É com essa finalidade que o presente trabalho foi desenvolvido.

Para a realização da pesquisa, em consonância com a bibliografia pesquisada, foram obedecidos os procedimentos que reduzissem problemas de interpretação e aumentassem 0 valor das conclusões. Inicialmente, houve a definição do foco do estudo a partir da elaboração da questão de pesquisa: quais 
asimplicarcẽes para a drâmica organizacional demicoepequenas em presas deconentesdaadbãadaestratéeja devínclosinterorcanizacionais? Posteriormente, definiu-se a abrangência dos estudos pesquisados: conjuntodeartigos pudicados no Encontro deEstudos sdreEmpreandedonismo eGesão deMicoePequanas Empresas em todasas suas eiç̃es (2000, 2001, 2003, 2005 e2008). Nessa etapa, cuidou-se para que os estudos selecionados tivessem como objetos de estudos pequenasemprascomúmulosinterorganizacionais etáveise utilizassem procedimentos metodológicos aproximados entre si, geralmente estudos de caso.

Para a análise, foram considerados os conceitos-chaves construídos a partir do referencial teórico sobre pequenas empresas, os quais foram reorganizadas em 3 dimensões:

- Dependência do empresário: diz respeito à simbiose entre o empresário e sua empresa, manifestada pelas categorias de centralização administrativa, autonomia de decisão e baixa profissionalização;

- Dinâmica interna: dimensão relativa às praticas gerenciais e aos recursos organizacionais. As categorias que a compõem são a adoção de sistemas produtivos defasados e a escassez de recursos, especialmente os financeiros;

- Dinâmica externa: dimensão que trata do relacionamento das pequenas empresas com 0 ambiente externo e está representada nas categorias de pouco poder de negociação e mercado restrito.

D efinidas as categorias, os artigos selecionados foram analisados de forma a identificar o modo como as relações interorganizacionais afetaram cada uma das categorias, segundo os relatos empíricos. 0 resultado dessa análise será descrito na seção seguinte.

IN FLUÊN CIA DO ESTABELECIMENTO DE VÍN CUL OS INTE RORGANIZACIONAIS ESTÁVEIS SOBRE A GESTÃO DE MICRO E PEQUENAS EMPRESAS

Nesta seção são comparadas as vantagens advindas da estratégia de rede com os elementos característicos das micro e pequenas empresas. Cada subitem trata de um conjunto de influências específicas sobre a gestão de PME , a saber: a dependência do empresário, a dinâmica interna e a dinâmica externa.

\section{Influência sobre a dependência do empresário}

Como já exposto, a autonomia e a centralização das decisões constituem-se em um fator derivado da ação empreendedora dos empresários. Todavia, a inserção em redes pode reduzir o âmbito de atuação do empresário sobre a própria empresa, mesmo que em escala muito variável. Entre os casos citados por Pacanhan et al. (2003), a formação de uma rede entre varejistas de material de construção é explícita quanto à elaboração de um planejamento estratégico comum e mesmo quanto à estrutura interna das lojas.

Todas as lojas passaram a contar com uma assessoria especializada a fim de comporem um layout único, integrando as cores da marca, a sua fachada e ambiente interno. Ao contrário da rede supermercadista, (...), essa rede utiliza a sua marca como nome principal das lojas, tanto em veículos de entrega como no material promocional e em seus luminosos, deixando em segundo plano suas marcas independentes, apesar de juridicamente serem distintas. A segunda meta foi a integração dos objetivos individuais de cada associado, culminando em um planejamento estratégico único para toda a rede" (PACANHAN et al., 2003, p. 13, grifos nossos).

Como exposto, há uma submissão relativa das empresas "juridicamente distintas" ao planejamento e ao padrão da rede.

Pode ocorrer também a participação em redes, mantendo-se maior autonomia. $\mathrm{O}$ artigo supracitado de Pacanhan et al. (2003) aborda o caso de uma rede entre varejistas supermercadistas que mantiveram grande autonomia, relegando à rede apenas parte das negociações das compras conjuntas e dos sistemas de concessão de crédito. Mesmo nesses casos, a menor delegação de papéis para a rede indica que o conceito de autonomia e centralização gerencial deve ser objeto de reflexão pela academia. Vale salientar que não se trata de autonomia e centralização apenas de aspectos operacionais, mas principalmente de aspectos estratégicos.

Observa-se também que essa delegação é uma necessidade para que o empresário faça parte da rede, constituída precisamente para assumir funções nas quais o estabelecimento de vínculos interorganizacionais estáveis pode obter melhor resultado. Não se trata de uma vontade da empresa de "delegar funções" à rede, mas de uma condição para 0 seu pertencimento a ela.

Outra característica comum às micro e pequenas empresas refere-se à gestão parcial, incompleta ou não profissional. As causas são relacionadas com escassez de recursos, participação de empresário em aspectos operacionais, falta de treinamento ou de conhecimento gerencial. Em todos esses aspectos a participação em redes pode contribuir para mudar essas características.

Perera, Guerra e Kimura (2003), estudando redes de farmácias, concluíram que as redes influenciam vários elementos da gestão das micro e pequenas empresas, independentemente de outros fatores, como localização, porte ou idade. Entre os artigos científicos, Gerolamo et al. (2005) indicam que uma das práticas e ações conjuntas entre os empresários do arranjo produtivo local de Ibitinga (SP) é 0 apoio administrativo às micro e pequenas empresas. Para tanto, conta-se com o apoio de entidades como o Sebrae, a Federação das Indústrias do E stado de São Paulo (FIESP) e o Sindicato da Indústria e Comércio de Bordados de Ibitinga SIND ICO BI. Rosa e Souza (2005) também descrevem o aperfeiçoamento gerencial de micro e pequenas empresas, mas por meio de processos de troca de experiências entre os próprios empresários, no caso do ramo de transporte de cargas. Souza e Fernandes (2001) sugerem ainda que o aperfeiçoamento gerencial pode ser condição necessária para a inserção das micro e pequenas empresas em redes que compartilham recursos, como os consórcios de exportação, por exemplo. 
Subjacente à concordância do desenvolvimento gerencial, são percebidos mecanismos distintos. Em Gerolamo et al. (2005), o desenvolvimento se dá por meio de um apoio externo, como uma benesse aos empresários aglomerados. Em oposição, em Rosa e Souza (2005), o processo de aperfeiçoamento na gestão ocorre pela interação social entre os participantes, como um fruto "natural" da associação. Em uma terceira perspectiva, Souza e Fernandes (2001) deixam a entender que 0 avanço das relações pode exigir que as empresas envolvidas adotem instrumentos de controle gerencial, fazendo com que o aprimoramento da gestão se torne uma condição sinequa nan para a cooperação.

INFLUÊ NCIA SOBRE A DINÂMICA INTERNA: ESCASSE $Z$ E DIFICULDADES DE ACESSO A RECURSOS

As características de escassez e dificuldade de acesso a recursos críticos são manifestadas nas empresas por meio de processos tecnológicos defasados, da dificuldade na obtenção de financiamento e da restrição de obtenção de consultorias.

No que se refere à superação da escassez e falta de acesso a recursos pelas micro e pequenas empresas, Silva, Leite e Sunderman (2008) destacam muitas possibilidades de ganhos advindos por meio do arranjo produtivo local de fogos de artifício de Santo Antônio do Monte (MG). Entre elas, destaca-se a construção de um laboratório de testes de produtos. Também nesse caso houve uma intensa participação do poder público.

Tsujiguchi e Câmara (2008), estudando empresas do polo de softwarede Londrina (PR), indicam que a colaboração entre empresários tem como principais utilidades o desenvolvimento e 0 aperfeiçoamento de produtos e processos. Esse resultado é corroborado por Hirata e Inácio Júnior. (2001) que, relatando a atuação de uma cooperativa agrícola destacou o desenvolvimento de técnicas e processos adaptados para a realidade dos pequenos produtores rurais. Todavia, enquanto os primeiros teóricos destacam as relações informais entre empresários como a fonte de desenvolvimento, os últimos enfatizam o papel central da cooperativa no desenvolvimento, a qual atuava de um modo mais independente dos associados.

Apesar dos benefícios apontados, os relatos diferem no que se refere à possibilidade de acesso a recursos. Segundo Hirata eInácio Júnior (2001), a cooperativa possibilitava o acesso a instituiçõ es de pesquisa, influenciava a política setorial e intermediava financiamentos. Por outro lado, Tsujiguchi e Camara (2008) destacam que há uma pequena relevância da rede em aspectos como exportação de produtos, obtenção de financiamentos e reivindicações políticas, e apoio financeiro para a rede. $\mathrm{E}$, mesmo havendo entidades de desenvolvimento tecnoló gico, a interação entre elas e a rede não é significativa:

Verificaram-se escassos laços multilaterais com outras instituições; baixa ou nenhuma intensidade de interação com outras organizações tais como: universidades, institutos de pesquisa (...), incubadoras de empresas (...), centros de qualificação profissional (...), instituições de testes e certificações, entidades de representação (...) e sindicais, órgãos de apoio e promoção (...) e entidades financeiras (...) (TSUJIGUCHI; CÂMARA, 2008, p. 12, grifos nossos).

Pela análise dos relatos, percebe-se que a superação das limitações de recursos se dá quando há uma coordenação dirigida nesse sentido, seja pelos próprios empresários seja por agentes externos, em particular o poder público. Essa afirmação é corroborada por Souza (1995) e Hoffmann, Morales e Floriani (2003), que indicam que para a realização de certas vantagens da aglomeração há necessidade da ação conjunta, não sendo suficiente a concentração territorial. E ssas vantagens obtidas por meio da ação conjunta são denominadas eficiência coletiva (SCHMITZ, 1997).

\section{INFLUÊNCIA SOBRE A DINÂMICA EXTERNA: POUCO PODER DE NEGOCIAÇÃO E MERCADO RESTRITO}

Talvez as vantagens mais evidentes do estabelecimento de vínculos interorganizacionais estáveis em redes sejam as relacionadas com a alteração do poder das micro e pequenas empresas no mercado. É importante ressaltar, porém, que este trabalho foca o estabelecimento de vínculos estáveis entre micro e pequenas empresas e não entre grandes e micro e pequenas empresas. Nessas últimas, as características de assimetria de poder e restrição de mercado são, ao contrário, mais evidenciadas, uma vez que as grandes empresas são as principais clientes, quando não únicas compradoras individuais e, por isso mesmo, o poder de negociação das PME é mínimo.

Rosa e Souza (2005, p. 2) apontam que o poder de negociação a partir da rede de transportadores favoreceu tanto na compra quanto na venda:

Na compra de caminhões em conjunto, por exemplo, conseguem diferenciais de preço que, isoladamente, não conseguiriam. Na contratação de fretes junto a grandes embarcadores de soja, obtêm poder de barganha por garantirem grande volume transportado, pontualidade nas entregas e disponibilidade e adequação de frota.

Corroboram esse resultado Pacanhan et al. (2003), que notaram o poder de resposta de micro e pequenas empresas em estudos de caso em duas redes distintas, em que houve em ambas aperfeiçoamento de serviços. No caso de uma rede de supermercados, a associação proporcionou o lançamento de serviços de crédito aos clientes, enquanto numa rede de lojas de materiais de construção a associação proporcionou a mudança na concepção dos negócios, transformando-as de depósitos em homecentess. E ssa mudança representa um aperfeiçoamento e uma aproximação do modo de operação de grandes empresas do setor com as quais as micro e pequenas empresas estavam em concorrência direta.

Observa-se que as redes funcionam como fontes de vantagem competitiva tanto em termos de escala quanto em termos de diversificação. No primeiro caso, as vantagens advêm da simples aglomeração de pedidos, enquanto no segundo há uma ampliação dos serviços ou produtos ofertados. 
Poderia ainda haver ganhos de escopo por meio da especialização, como apresentado por Souza e Fernandes (2001), como um potencial do consórcio exportador. Assim, em resumo, percebe-se que as redes de micro e pequenas empresas proporcionam ganhos pelo equilíbrio de poder, de ganhos de escala e por meio de acesso a novos mercados.

\section{A INFLUÊ NCIA DAS ESTRATÉGIAS DE REDE SOBRE A GEST ÃO DE PEQUENAS EMPRESAS}

Pela análise dos relatos empíricos, apresentada nas seções anteriores, foi possível elaborar um quadro analítico no qual são apresentadas as relações entre os elementos característicos das micro e pequenas empresas e as possíveis influências da adoção da estratégia de vínculosinterorganizacionais estáveis. Adicionalmente foram identificados os mecanismos pelos quais essa influência pode ocorrer (Quadro1).

As linhas do Quadro foram especificadas a partir do referencial teórico sobre pequenas empresas, enquanto as colunas foram construídas tendo em vista o foco da pesquisa. O s resultados da análise dos artigos preenchem o "meio" e representam as potenciais relações funcionais entre o estabelecimento de vínculos interorganizacionais e as mudanças nas caractenísticas das micro e pequenas empresas. ser citados os itens de campanha publicitária e a adoção de padrões estruturais de pontos de venda. Por outro lado, a empresa pode alcançar níveis mais elevados de profissionalização, também por decorrência da ação das redes.

Em termos de dinâmica interna, chama a atenção os elementos de gestão incompleta e escassez de recursos: é possível que micro e pequenas empresas estabeleçam vínculos interorganizacionais estáveis, adotem mais plenamente instrumentos gerenciais, executem processos operacionais e produtivos mais eficientes e usufruam de maior acesso a recursos críticos, comparativamente a outras empresas.

No que se refere à dinâmica externa, é possível que a participação em redes aumente a influência das MPE sobre 0 ambiente, tanto pela reunião de recursos quanto pela divisão social de trabalho dentro da rede. Como resultado, podese alcançar a participação em mercados mais amplos e aumentar o poder de negociação.

Dentro das categorias previamente estabelecidas, foi possível identificar importantes mecanismos por meio dos quais as redes influenciam a dinâmica de seus membros: imposição, concessão e aquisição ou desenvolvimento.

Pelo mecanismo de imposição, as micro e pequenas empresas adotam novas práticas por necessidade da rede, por

\begin{tabular}{|c|c|c|c|c|}
\hline Dimensões & Características & $\begin{array}{c}\text { Beneficios ou } \\
\text { impactos esperados }\end{array}$ & Causas ou fontes & Mecanismo \\
\hline \multirow{3}{*}{$\begin{array}{l}\text { Dependência do } \\
\text { empresário }\end{array}$} & $\begin{array}{l}\text { Centralização e auto- } \\
\text { nomia de decisão }\end{array}$ & Menor autonomia & $\begin{array}{l}\text { Alteração do modelo de negócio, } \\
\text { delegação de ações para a rede }\end{array}$ & Imposição \\
\hline & \multirow[b]{2}{*}{$\begin{array}{c}\text { Baixa } \\
\text { profissionalização }\end{array}$} & \multirow{2}{*}{$\begin{array}{c}\text { Maior } \\
\text { profissionalização }\end{array}$} & Treinamento gerencial & Aquisição \\
\hline & & & $\begin{array}{c}\text { Aprendizagem por meio da } \\
\text { interação }\end{array}$ & D esenvolvimento \\
\hline \multirow{3}{*}{ Dinâmica intema } & \multirow{2}{*}{$\begin{array}{l}\text { Adoção de sistemas } \\
\text { produtivos } \\
\text { defasados }\end{array}$} & $\begin{array}{l}\text { Auxílio na solução de } \\
\text { problemas técnicos }\end{array}$ & $\begin{array}{c}\text { Interação com instituições de } \\
\text { pesquisa e consultorias }\end{array}$ & $\begin{array}{l}\text { Aquisiçãa ou } \\
\text { concessão }\end{array}$ \\
\hline & & $\begin{array}{l}\text { Aperfeiçoamento } \\
\text { tecnológico de } \\
\text { produtos }\end{array}$ & $\begin{array}{l}\text { Cooperação, aprendizagem ou } \\
\text { desenvolvimento conjunto }\end{array}$ & Desenvolvimento \\
\hline & $\begin{array}{l}\text { Escassez de recursos } \\
\text { financeiros }\end{array}$ & $\begin{array}{l}\text { Acesso a linhas de } \\
\text { crédito }\end{array}$ & $\begin{array}{c}\begin{array}{c}\text { Canalização de recursos } \\
\text { governamentais }\end{array} \\
\end{array}$ & $\begin{array}{l}\text { Aquisição ou } \\
\text { Concessão }\end{array}$ \\
\hline \multirow{4}{*}{ Dinâmica extema } & \multirow{3}{*}{$\begin{array}{l}\text { Pouco poder de } \\
\text { negociação }\end{array}$} & Equilíbrio de poder & $\begin{array}{c}\text { Ampliação dos serviços ofertados; } \\
\text { Maior poder na negociação nas } \\
\text { compras }\end{array}$ & Aquisiç̧ão \\
\hline & & $\begin{array}{c}\text { Ganho de escala na } \\
\text { compra e na produção }\end{array}$ & $\begin{array}{c}\text { Compras conjuntas, vendas } \\
\text { conjuntas }\end{array}$ & Aquisição \\
\hline & & Economia de Escopo & Participação em feiras & Aquisição \\
\hline & Mercado restrito & $\begin{array}{l}\text { Acesso a novos } \\
\text { mercados }\end{array}$ & Exportação & $\begin{array}{l}\text { Desenvolvimento ou } \\
\text { aquisiçãa }\end{array}$ \\
\hline
\end{tabular}

Quadro 1: Mecanismos geradores de vantagens competitivas por meio de redes de micro e pequenas empresas

Fonte: Elaborado pelos autores, com base nos dados da pesquisa.

As influências da adoção de vínculos interorganizacionais estáveis se deram em todas as categorias analisadas: na dependência do empresário, na dinâmica interna e na dinâmica externa das MPE.

Quanto à dependência do empresário, ele pode se ver obrigado a ceder parte da sua autonomia por delegação de certas decisões para o nível da rede. Como exemplos, podem coerção ou não. A imposição ocorre quando há critérios de seleção, formais ou não, de participantes da rede. Esse mecanismo foi percebido nos casos de consórcio de exportação (SO UZA; FERNANDES, 2001).

Pelo mecanismo de concessão, as micro e pequenas empresas obtêm vantagens ou benefícios advindos de ações de outras organizações (como grandes empresas ou entida- 
des governamentais). Excluem-se aqueles benefícios advindos da própria organização das micro e pequenas empresas. Foram percebidos esses processos principalmente nos arranjos produtivos locais, em que o poder público e o Sebrae atuam fortemente por meio de financiamento direto ou subsídios.

A aquisição e 0 desenvolvimento são alterações ou benefícios decorrentes da interação exclusiva entre micro e pequenas empresas. Q uando decorrem de ações intencionais são denominadas aquisição, quando provenientes de ações não intencionais são chamadas de desenvolvimento. As aquisições manifestam-se principalmente em centrais de compra ou centrais de negócio e os processos de desenvolvimento ocorreram em todos os casos, dado que são mecanismos oriundos da interação social entre os empresários.

Assim, pode-se perceber que a influência das redes sobre a gestão das MPE é ampla e não ocorre de maneira homogênea. A o contrário, os modos de influência são distintos, podendo haver, inclusive, necessidade de interferência de agentes externos.

A seguir são apresentadas as considerações finais bem como ideias de pesquisas oriundas das análises apresentadas.

\section{CON SIDE RAÇÕE S FINAIS}

Este artigo identificou as potenciais influências da formação de redes entre pequenas empresas sobre a gestão dessas organizações, especialmente sobre como as relações interorganziacionais podem contribuir para a superação das limitações características do pequeno porte. Para tanto, foram discutidas as especificidades das PME , o relacionamento interorganizacional como estrutura favorável à competitividade dessas organizações e, por meio de análise dos anais do principal encontro acadêmico brasileiro sobre pequenas empresas e empreendedorismo, foram identificados fontes e mecanismos de influência.

Entre as contribuições deste artigo, nota-se que as redes podem interferir em elementos considerados nucleares às pequenas empresas, como a dependência do empresário e sua autonomia para os rumos da empresa, as restrições de recursos e a sua fraqueza diante do ambiente dominado por grandes empresas. De maneira geral, observou-se que as redes provocam alterações no sentido de maior racionalidade econômica e efetividade organizacional, como foram os casos de maior profissionalização e maior poder de negociação perante os fornecedores.

Há de se notar também a identificação de mecanismos pelos quais os elementos caractenísticos das micro e pequenas empresas podem sofrer influência da adoção da estratégia de estabelecimento de vínculos interorganizacionais estáveis. A identificação de diferentes mecanismos indica que a relação empresa-rede é complexa, podendo assumir diferentes configurações. Assim, os empresários que pretendem absorver os benefícios oriundos das relações interorganizacionais devem estar preparados para lidar com os diferentes modos de interação e conscientizar-se de que sua postura diante de sua empresa também sofrerá alterações. Em outras palavras, os empresários devem saber que o relacionamento estável de longo prazo requer adaptações, diferentemente das relações comerciais pontuais de compra e venda.

Portanto, conclui-se que o estabelecimento de vínculos interorganizacionais estáveis pode influenciar as PME, fornecendo vantagens por meio das economias de aglomeração (externalidades) ou pela obtenção de benefícios não alcançáveis pela empresa caso ela não atuasse de modo isolado. Em suma, as redes podem ser fontes importantes de competitividade para as pequenas empresas.

0 artigo também apresenta limitações. A principal delas é que - considerando que a base de dados aqui analisada não foi desenvolvida para as mesmas finalidades do presente trabalho - as afirmaçõ es apresentadas limitam-se aos estudos apresentados em todas as edições do EGEPE. Assim, propõe-se que novas pesquisas sejam realizadas para que elas sejam verificadas para estudos delineados com metanálise, tal como sugerem Lovatto, Lehnen e Andretta (2007). Também como continuidade deste estudo espera-se desenvolver novas metanálises, ampliando a base de estudos e incorporando também outras fontes, particularmente as internacionais.

Por fim, novas questões de pesquisa podem ser encaminhadas, a saber: em quais áres há maior ddeeação de funções para a rece, equais as decisães etratégicas queos empresánios mais redutamem dleegr? Há diferença na eficádia das vantagens conformea natureza dos procssos(meanismos)? Quaisáneas au aspetos sãomis influeniados pela rede? Qual a participaçãodoempresániona definição dos fatares da rede?

Espera-se que, a partir do presente estudo, novos trabalhos possam ser realizados no sentido de melhor entender a influência das redes para a dinâmica de pequenas empresas.

\section{REFERÊNCIAS}

BALESTRIM, A.; VARG AS, L. M. A. D imensão estratégica das redes horizontais de PMEs: teonizações e evidências. RevistadeAdministração Contemprânœ, Curitiba, v. 8, p. 203-227, 2004. Edição Especial.

BARBOSA, J. D.; TEIXEIRA, R. M. G estão estratégica nas empresas de pequeno e médio porte. CadamodePesquisas emAdministração São Paulo, v. 10, n. 3, p. 31-42, jul./ set. 2003.

BEGNIS, H. S. M.; PEDROZO, E. Á.; ESTIVALETE, V. de F. B. Cooperação enquanto estratégia segundo diferentes perspectivas teóricas. In: ENCONTRO NACIONAL DA ASSOCIAÇÃO NACIONAL DOS PRO GRAMAS DE PÓS-GRADUAÇÃO EM AD MINIST RAÇÃO, 29, 2005, Brasilia. Anais... Brasília: ANPAD, 2005.

BE ST, M. The new compeition Canbridge Harvard University, 1990. $296 \mathrm{p}$.

BOTELHO, D. e MACERA, A. Análise metateórica de teses e dissertações da área de marketing apresentadas na EAESP-FGV (1974-1999). In: ENCONTRO NACIONAL DA ASSOCIAÇÃO NACIONAL DOS PROGRAMAS DE PÓS-GRADUAÇÃO EM AD MINISTRAÇÃ O, 25, 2001, Campinas. Anais.. Campinas: ANPAD, 2001.

BRASIL. Lei no 9.841, de 5 de outubro de 1999. Institui o Estatuto da Microempresa e da Empresa de Pequeno Porte, dispondo sobre o tratamento jurídico diferenciado, simplificado e favorecido previsto nos arts. 170 e 179 da Constituição Federal. DiánioOficial [da] República Fedkativa doBrasil, Brasilia, 7 de outubro de 1999. 
BRITTO, J. Cooperação interindustrial e redes de empresas. In: KUPFER, D.; HASENCLEVER, L. Economiaindustrial: fundamentos teóricos e práticas no Brasil. Rio de Janeiro: Campus, 2002, cap. 15, p. 345-388.

BRO DECK, A. F. et al. Alinhamento entre O bjetivos O rganizacionais e Sistemas de Informação: Um Estudo de Múltiplos Casos. In: ENCONTRO NACIO NAL DA ASSOCIAÇÃO NACIO NAL D O S PROG RA MASD E PÓ S-G RADUAÇÃO EM AD MINIST RAÇÃO, 27, 2003, Atibaia. Anais.. Brasília: ANPAD, 2003.

BUJD O SO, Y. L. V. et al A academia e a divisão social do trabalho na enfermagem no setor público: aprofundamento ou superação? Ciênia deSaúdeCdeiva, Rio de Janeiro, v. 12, n. 5, 2007. D isponível em:<http:/ / www.scielosp.org/ scielo.php?script=sci_arttext\&pid= S1413-81232007000500034\&lng=en\&nrm=iso >. A Acesso em: 07 Oct 2008.

CASSIOLATO, J. E.; LASTRES, H. M. M. O foco em arranjos produtivos locais de micro e micro e pequenas empresas. In: CASSIO LATO, J. E.; LASTRES, H. M. M; MACIEL, L. M. (O rg.). Pequena empresa: cooperação e desenvolvimento local. Rio de Janeiro, RJ: Relume D umará, 2003, p. 21-34.

CA STE LLS, M. A sociєladeemrede SãoPaulo Paz e Terra, 1999. v. 1, $617 \mathrm{p}$.

CEZARINO, L. O.; CAMPOMAR, M. C.Vantagem competitiva para micro, pequenas e médias empresas: clusters e APLS In: ENCONTRO DE ESTUD OS SO BRE EMPREENDED ORISMO E GESTÃO DE MICRO E PEQUENAS EMPRESAS, 4, 2005, Curitiba. Anais.. Curitiba, 2005, p. 1315-1326.

CONFEDERAÇÃO NACIONAL DA IND ÚSTRIA. Indicadbres de competitividade na indústria brasileira: micro e pequenas empresas. Brasília: CNI-SEBRAE, 2006. p. 134.

COUTIN HO, L. Prefácio. In: FERRAZ, J. C.; KUPFER, D.; HAG UENAUER, L. Madeinbrazil: desafios competitivos para aindústria Rio de Janeiro: Campus, 1995. p. XXV-XXXI.

D O LABELA, F. O segebdeLuísa: uma idèa, uma paixãoeumplamode negóios como nasce o empreendedor e se cria uma empresa. São Paulo: Cultura, 1999.

FARAH JÚNIOR, M. F. A terceira revolução industrial e o novo paradigma produtivo: algumas considerações sobre 0 desenvolvimento industrial brasileiro nos anos 90 . Reista da FAE, Curitiba, v. 3, n. 2, p. 45-61, maio/ ago. 2000.

FERRAZ, J. C.; KUPFER, D.; HAG UENAUER, L. Madein brazil: desafios competitivos para a indústria. Rio de Janeiro: Campus, 1995, $386 \mathrm{p}$.

FO NTOURA, M. A vida dos downsizados. ReistaExame São Paulo, v. 29, n. 10, p. 70-76, mai. 1996.

GAZETA MERCANTIL, Pão deagúcar encontra umjeito de crescer sem gastar, São Paulo, 23 out. 2007. D isponível em: <http:/ / indexet. gazetamercantil.com.br/ arquivo/ 2007/ 10/ 23/ 33/ Pao-de-Acucarencontra-um-jeito-de-crescer-sem-gastar.html>. Acesso em: 19 ago. 2008.

GERO LAMO, M. C. et al. C. R. Aglomeração de pequenas e médias empresas como ambiente propício à melhoria de desempenho caracterização do arranjo produtivo local do setor de confecção de bordados de Ibitinga In: ENCONTRO DE ESTUD OS SOBRE EMPREENDEDORISMO E GESTÃO DE MICRO E PEQUENAS EMPRESAS. 4, 2005, Curitiba, Anais... Curitiba: 2005, p. $1245-1258$.

GIMENEZ, F. O estrategistama pequenaempresa Maringá: Universidade Estadual de Maringá, 2000, 164 p.
GOSLING, M.; GONÇALVES, C. A. Ideias metodológicas dos autores de estratégia dos enanpads: uma meta-análise. ReistaEletrônica deAdminsitração Porto Alegre, v. 10, n. 5, 2004.

GRAND ORI, A.; SODA, G. Inter-firm networks: antecedents, mechanisms and forms. Organization Studes Berlim, v. 16, n. 2, p. 183-214, spring 1995.

HIRATA, N.; INÁCIO JÚNIOR, E. A importância de uma rede institucional de comunicação para inovação: 0 caso da cooperativa agrícola de cotia (cac). In: ENCONTRO DE ESTUDOS SOBRE EMPREENDEDORISMO E GESTÃO DE MICRO E PEQUENAS EMPRESAS, 2, 2001, Londrina. Anais.. Londrina: 2001, p. 959-972.

HO FFMANN, V.; MO RALES, F. J. M.; FLORIANI, D. Cooperação entre empresas em aglomerações territoriais. In: ENCONTRO DE ESTUD OS SOBRE EMPREENDEDORISMO E GESTÃO DE MICRO E PEQUENAS EMPRESAS, 3, 2003, Brasília. Anais... Brasília: UEM/ UEL/ UnB, 2003, p. 723-734.

JABBOUR, C. J. C.; SANTOS, F. C. A.; BARBIERI, J. C. Gestão ambiental empresarial: um levantamento da produção científica brasileira divulgada em periódicos da área de administração entre 1996 e 2005. Revista deAdministração Contemporânea, Curitiba, v. 12, n. 3, 2008. D isponível em: <http:// www.scielo.br/ scielo.php?script= sci_arttext\&pid $=$ S1415- $65552008000300005 \& \operatorname{lng}=\& n r m=$ iso $>$. Acesso em: 07 de 2008.

KASSAI, J. R.; KASSAI, S. Balanço perguntado: uma solução para as micro e pequenas empresas. In: CONGRESSO BRASILEIRO DE CUSTO S. 8, 2001, São Leopoldo. Anais... São Leopoldo/ RS, 2001.

KASSAI, S. As empresas de pequeno porte ea contabilidade. Cadamos deEstudos São Paulo, v. 9, n. 15, p. 60-74, jan./ jun. 1997.

LEONE, N. M. C. P. G. As especificidades das pequenas e médias empresas. Revista de Administração São Paulo, v. 34, n. 2, p. 91-94, abr./ jun. 1999.

LIMA, E. O. As definições de micro, pequena e média empresas brasileiras como base para a formulação de políticas públicas. In: ENCONTRO DE ESTUD OS SO BRE EMPREENDED ORISMO E GESTÃO DE MICRO E PEQUENAS EMPRESAS, 2., 2001, Londrina. Anais.. Londrina, PR: 2001, p. 421-436.

LIMA, J. B. Temas de pesquisa e desafios da produção científica sobre PME. In: ENCONTRO DE EMPREENDEDORISMO E GESTÃO DE PEQUENAS EMPRESAS, 1, 2000, Maringá. Anais.. Maringá: Universidade Estadual de Maringá,/ Universidade Estadual de Londrina, 2000, p. 1-20.

LOVATTO, P. A.; LEHNEN, C. R.; ANDRETTA, I. et al. Metaanálise em pesquisas científicas: enfoque em metodologias. Revista Brasilera Zodearia, v. 36, suppl. p. 285-294, Jul. 2007.

MCCORMICK, J; RODNEY, P; VARCOE, C. Reinterpretations across studies: an approach to meta-analysis. Qualitativehealthrearch v. 13, n. 7, p. 933-944, sep. 2003.

MILES, R. E.; SNOW, C. C. Causes of Failure in Network Organizations. Califomia Management Review, v. 34, n. 4, p. 53-72, Summer 1992.

MINTZBERG, H.; AHLSTRAND, B.; LAMPEL, J. Safán deestratéga um roteiro pela selva do planejamento estratégico. Porto Alegre, RS: Bookman, 2000, 299 p.

MIRAND A, J. C. Abetura comerial, restruturaçãoindustrial eexpotaçoes brasileras ma dérada de 1990. Brasilia: IPEA, 2001.

NAJBERG, S.; MORAES, R. M.; IKEDA, M. A crescente participação das micro firmas no total de estabelecimentos e no emprego. InfarmeseBNDES. Rio de Janeiro, n. 36, dez. 2002. 
NOHRIA, N. Is a network perspective a useful way of studying organizations? In: NO HRIA, N. ECCLES, R. G. (Ed.). Networksand arganizations structure, form, and action. Boston, Massachusetts: Harvard Business School, 1992, cap.1, p. 1-22.

OLAVE. M. E. L.; AMATO NETO, J. Redes de cooperação produtiva: uma estratégia de competitividade e sobrevivência para pequenas e médias empresas. Gestão\& Prouluãa São Carlos, v. 8, n. 3, p. 289-303, dez. 2001.

PACANHAN, M. N. et al. Redes asso ciativistas no varejo: um estudo sobre as particularidades do modelo cooperativo como estratégia competitiva para os pequenos varejistas. In: ENCONTRO DE ESTUD O S SOBRE EMPREENDEDORISMO E GESTÃO DE MICRO E PEQUENAS EMPRESAS. 3, 2003, Brasília. Anais.. Brasília: UEM/ UEL/ UnB, 2003, p. 749-769.

PERERA, L. C. J.; G UERRA, J. A. de P.; K IMURA, H. Estratégia de gestão para micro e micro e pequenas empresas do setor farmacêutico de Franca, SP: alternativa de sobrevivência. In: ENCONTRO DE ESTUD OS SO BRE EMPREENDED ORISMO E GESTÃO DE MICRO E PEQUENAS EMPRESAS, 3, 2003, Brasília. Anais.. Brasília: UEM/ UEL/ UnB, 2003, p. 440-450.

PO RTER, M. E. A vantagem competitiva das naçoes Rio de Janeiro: Campus, 1989. $897 \mathrm{p}$.

PORTER, M. E. Estratégia competitiva: técnicas para análise de indústrias e da concorrência, Rio de Janeiro: Campus, 1986.

POWELL, W.W. Neither market nor hierarchy: networks forms of organization. In: CUMMINGS, L. L.; SHAW, B. (Ed.). Research in Organizaianal Behavior. G reenwich, CT: JAI, v. 12, p. 295-336, 1990.

RATTNE R, H. (O rg). Pequena empresa: 0 comportamento empresarial na acumulação e na luta pela sobrevivência. São Paulo: Brasiliense/ Brasília: Conselho Nacional de Desenvolvimento Científico e Tecnológico, 1985

RO D RIG UES, C. A abordagem processual no estudo da tradução: uma meta-análise qualitativa. Cadłmos de Tradução v. 2, n. 10, p. 2357, 2002.

RO SA, A. V. A.; SO UZA, A. Cooperação coordenada: uma estratégia de crescimento sustentável para micro e pequenas empresas de transporte rodoviário de cargas no Brasil. In: ENCONTRO DE ESTUDOS SOBRE EMPREENDEDORISMO E GESTÃO DE MICRO E PEQUENAS EMPRESAS, 4, 2005, Curitiba. Anais.. Curitiba: 2005, p. 1267-1278.

ROVERE, R. L. Estratégias competitivas e gestão de informações em sistemas de MPME. In: POLÍTICAS PARA SISTEMAS PRODUTIVOS LOCAIS DE MPME (MICRO PEQUENAS E MÉD IAS EMPRESAS, 2002, Mangaratiba. Anais.. Rio de Janeiro: IE/ UFRJ, 2002, p.1-22.

SANTOS, D. D. dos; TEIXEIRA, R. M. Redes interorganizacionais de pmes: fatores de cooperação e aprendizado. In: ENCONTRO DE ESTUDOS SOBRE EMPREENDEDORISMO E GESTÃO DE MICRO E PEQUENASEMPRESAS, 4, 2005, Curitiba. Anais.. Curitiba: 2005, p. 1289-1300

SANTOS, F. M.; EISE NHARDT, K. M. Organizational boundaries and theories of organization. Organization Saience, v. 16, n. 5, Sep./ Oct. 2005.

SCHMITZ, H. Eficiência coletiva: caminho de crescimento para a indústria de pequeno porte. EnsaiosFEE, Porto Alegre, v. 18, n. 2, p. 164-200, 1997.

SERVIÇO BRASILEIRO DE APOIO À MICRO E PEQUENA EMPRESA. Temoderefê̂niaparaaturẫodosedraeemamanjosprodutivos loais 2003. D isponível em: <http:/ / www.biblioteca.sebrae.com. br/ bte/ bte.nsf/ D owContador?O penAgent\&unid= 50533C 7F21014E5F03256FB7005C40BB>. Acesso em: 24 jun. 2007.

SERVICOO BRASILEIRO DE APOIO À MICRO E PEQUENA EMPRESA. Critérios e concitos para dassificação de empresas. 2008. D isponível em: <http:/ / www.sebrae.com.br/ customizado/ estudose-pesquisas/ bia-97- criterio s-e-conceitos-para-classificacao-deempresas/ BIA_97/ integra_bia>. Acesso em: 08 jun. 2008.

SILVA, I. C. da; LEITE, R. S.; SUNDERMANN, J. Benefícios da aglomeração industrial: uma análise do arranjo produtivo local de Santo Antônio do Monte - MG. In: ENCONTRO DE ESTUD OS SO BRE EMPREENDEDORISMO E GESTÃO DE MICRO E PEQUENAS EMPRESAS, 5, 2008, São Paulo. Anais.. São Paulo: 2008.

SILVA, V. L. Diagósticodbníved detendogjadainformaçãoedossistemasde

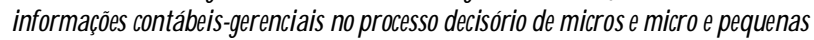
empresas do ramo de confexcẽes do mmiápiodeCdatina - ES. 2002. 147 p. Dissertação (Mestrado em Engenharia da Produção) - Universidade Federal de Santa Catarina. Florianópolis, SC.

SO UZA, G. B. de; FE RNAND ES, F. C. F. Análise da relação entre aglomerado industrial e empresa virtual no contexto de um consórcio exportador. In: ENCONTRO DE ESTUDOS SOBRE EMPREENDEDORISMO E GESTÃO DE MICRO E PEQUENAS EMPRESAS, 2, Londrina. Anais... Londrina, PR: 2001, p. $492-504$.

SO UZA, M. C. Pequenas emédias empresas na restruturacão industrial. Brasília: Sebrae, 1995, 257 p.

TAVARES, B.;FERREIRA, M. A. M.;LIMA, A. A.T. F. C. Identificação e agrupam ento de fatores de relevância na investigação das práticas de gestão das micro e pequenas empresas. In: ENCONTRO DE ESTUD OS SOBRE EMPREENDEDORISMO E GESTÃO DE MICRO E PEQUENAS EMPRESAS, 5, 2008, São Paulo. Anais.. São Paulo, 2008.

TAVARES, B.; MESQUITA, D. L.; CASTRO, C. C. Evidências de indução e mimetismo nos Arranjos Produtivos Locais pela ação institucional do Sebrae. In: SIMPÓSIO DE EXCELÊNCIA EM GESTÃO E TECNOLOGIA - SEG eT. 4, 2007, Resende. Anais.. Resende: Associação Educacional Dom Bosco, 2007.

TSUJIG UCHI, F. Y.; CÂMARA, M. R. G. da. Relações em rede nas micro e micro e pequenas empresas de software de londrina. In: ENCONTRO DE ESTUD OS SO BRE EMPREENDED ORISMO E GESTÃO DE MICRO E PEQUENAS EMPRESAS, 5, 2008, São Paulo. Anais... São Paulo, 2008.

WELSH, J.; WHITE, J. F. A small business is not a little big business. HarvardBusiness Review, Boston, v. 59, n. 4, p. 18-32, 1981.

WILLIAMSON, O. E. Theeconomicinstitutions of captalism London: Free, 1985.

WOMACK, J. P.; JONES, D. T.; RO OS, D. A máquima quemiduu o munda Rio de Janeiro: Campus, 1992.

Data de Submissão: 06/ 07/ 2009

Data de Aprovação: 26/ 11/ 2010 